\title{
Utility of Real-Time 3-Dimensional Transesophageal Echocardiography in the Assessment of Mitral Paravalvular Leak
}

\author{
Antonio Arribas-Jimenez, MD, PhD; Juan C Rama-Merchan, MD, PhD; Manuel Barreiro-Pérez, MD; \\ Soraya Merchan-Gómez, MD; Alberto Iscar-Galán, MD; Ana Martín-García, MD, PhD; \\ Felix Nieto-Ballestero, MD, PhD; Esther Sánchez-Corral, MD; Javier Rodriguez-Collado, MD; \\ Ignacio Cruz-González, MD, PhD; Pedro L Sanchez, MD, PhD
}

\begin{abstract}
Background: Mitral paravalvular leak (PVL) is a potential complication of surgical valve replacement procedures. Real-time 3D transesophageal echocardiography (RT-3DTEE) has emerged as an efficient tool for providing essential information about the anatomy of mitral PVLs compared with 2DTEE findings. The purpose of this study was to evaluate the utility of RT-3DTEE in the assessment of mitral PVLs.
\end{abstract}

Methods and Results: The 3D characteristics of PVLs were recorded and compared with 2D findings. We included 34 consecutive patients with clinical suspicion of mitral PVL in the study. Mitral PVLs were detected in 26 patients (76\%); 26 PVLs were identified by 2DTEE and 37 by RT-3DTEE. Moderate or severe mitral regurgitation was present in 23 patients (88\%). The most common PVL locations were the septal and posterior regions. The median PVL size measured by RT-3DTEE was $7 \mathrm{~mm}$ long $\times 4 \mathrm{~mm}$ wide. The median vena contracta of defect measured by 2DTEE and RT-3DTEE was $5 \mathrm{~mm}$ and $4 \mathrm{~mm}$, respectively. The median effective regurgitant orifice area of defect measured by RT3DTEE was $0.36 \mathrm{~cm}^{2}$. The defect types were "oval" (54\%), "round" (35\%), "crescentic" (8\%) and highly irregular (3\%).

Conclusions: Compared with 2DTEE, RT-3DTEE provided detailed descriptions of the number, location, size and morphology of PVLs, which is essential for planning and guiding the potential corrective techniques. (Circ $J$ 2016; 80: 738-744)

Key Words: Mitral regurgitation; Paravalvular leak; Real-time 3D transesophageal echocardiography; 2D transesophageal echocardiography

$\mathbf{P}$ aravalvular leaks (PVLs: abnormal communication between the cardiovascular chambers adjacent to a prosthetic valve) are a potential complication of surgical valve replacement procedures. ${ }^{1}$ The incidence of mitral PVLs, including small non-significant jets, is estimated to be as high as $17 \%$ and is more frequent when there is severe annular calcification, or following endocarditis. ${ }^{2-4}$ PVL is most commonly observed with mechanical valves, followed by bioprosthetic valves. The majority of PVL are crescent, oval or roundish-shaped and their track can be parallel, perpendicular or serpiginous. ${ }^{5-8}$

Many patients remain asymptomatic and do not require further surgical intervention. However, symptomatic patients often have associated heart failure, hemolytic anemia, arrhythmias, and infective endocarditis. ${ }^{9}$ Historically reoperation has been the standard treatment, but it is associated with higher morbidity and mortality., ${ }^{2,410}$ Transcatheter approaches to treatment of PVL have been recently proposed, especially in highrisk patients, and are increasingly performed in experienced centers. ${ }^{11-13}$

Echocardiography remains the main modality for the diagnosis of the PVL. Evaluation of the PVL by transthoracic echocardiography is difficult because of technical challenges. Although 2-dimensional transesophageal echocardiography (2DTEE) is very sensitive in accurately identifying the presence of PVL $(88 \%),{ }^{14}$ setting the number, extent, shape and exact anatomical location of the PVL can be very challenging. ${ }^{15,16}$ Real-time 3-dimensional TEE (RT-3DTEE) is a novel imaging technique based on the acquisition and display of volumetric data sets in the beating heart. This permits a comprehensive evaluation of cardiac anatomy and function from a single acquisition. ${ }^{17-20}$ Several studies have demonstrated the concordance

Received July 26, 2015; revised manuscript received November 30, 2015; accepted December 13, 2015; released online January 26,

2016 Time for primary review: 30 days

Cardiology Department, University Hospital of Salamanca, IBSAL, Salamanca, Spain

The first two authors contributed equally to this work and should be considered co-first authors (A.A.-J., J.C.R.-M.).

Mailing address: Antonio Arribas-Jimenez, MD, PhD, Cardiology Department, University Hospital of Salamanca, IBSAL, 37007, Paseo

de San Vicente, Salamanca, Spain. E-mail: aarribasj@yahoo.es

ISSN-1346-9843 doi:10.1253/circj.CJ-15-0802

All rights are reserved to the Japanese Circulation Society. For permissions, please e-mail: cj@j-circ.or.jp 


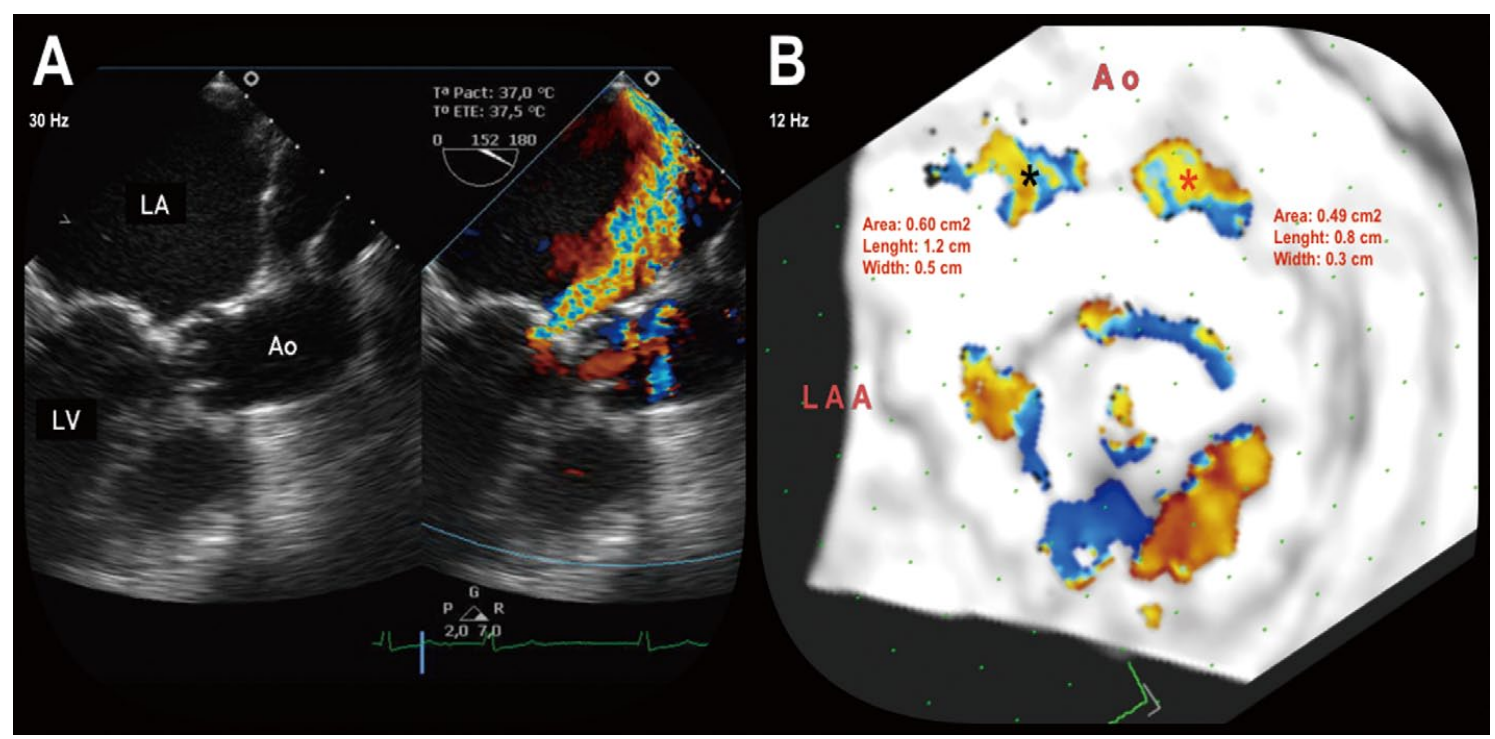

Figure 1. Mitral paravalvular leak (PVL) detected by 2DTEE and RT-3DTEE. (A) 2DTEE color-Doppler imaging showing an anterior mitral PVL with severe paravalvular regurgitation. (B) RT-3DTEE color-Doppler imaging of the same patient with black asterisk identifying an anterior (11 o'clock) PVL and red asterisk identifying a septal (1 o'clock) PVL. Note that only 1 PVL was identified by 2DTEE whereas 2 PVLs were identified by RT-3DTEE. Measurements of the length, width, and area were performed by planimetry using the QLAB multiplanar reconstruction tool (Philips Medical Systems). LA, left atrium; LV, left ventricle; Ao, aorta; LAA, left atrial appendage; RT, real time; TEE, transesophageal echocardiography.

between RT-3DTEE images and the real anatomy, and the superiority of RT-3DTEE over 2DTEE. ${ }^{18,21-25}$ This can be important in deciding whether the patient will undergo a surgical or transcatheter approach for the correction of the paravalvular regurgitation.

The purpose of this study was to evaluate the utility of RT3DTEE in the assessment of PVL.

\section{Methods}

\section{Patient Population and Echocardiographic Examination}

The study group comprised 34 consecutive patients with clinical suspicion of mitral PVL (presence of the mitral valve prosthesis and signs and symptoms of congestive heart failure and/or significant hemolysis) referred to the echocardiography laboratory. After providing informed consent, patients were simultaneously examined under sedation (1-2 mg mydazolam) with 2DTEE and RT-3DTEE. All echocardiographic studies were conducted with a Philips iE33 ultrasound system and an X7-2t transesophageal transducer (Philips Medical Systems, Andover, MA, USA). Heart rates of all patients were maintained between 60 and 80 beats $/ \mathrm{min}$. To recognize a PVL, 2DTEE and RT-3DTEE were carefully performed with a frame rate as high as possible in each patient. ${ }^{26}$ The $3 \mathrm{D}$ zoom mode and full-volume wide-angle acquisition mode were used to acquire the $3 \mathrm{D}$ volumetric datasets of the prosthetic valve and the paravalvular defects. All 3D echocardiographic loops included at least 3 cardiac cycles. 2D and 3D images were transferred to the Philips Xcelera workstation. All images were analyzed by blinded, experienced echocardiographers.

The number of PVLs recorded was based on data acquired from 2DTEE, RT-3DTEE volume images and full-volume 3D color-Doppler findings (Figure 1). Echocardiographic images were presented in the "surgical view", with the aortic valve at the top of the mitral valve prosthesis (12 o' clock), the left atrial appendage at 9 o'clock and the medial commissure at the 3 o'clock position. Thus, according to its position on this virtual clock, the location of each PVL was reported (Figure 2A). ${ }^{27,28}$

The severity of each PVL was evaluated by 2DTEE and RT-3DTEE using several parameters (Table 1): ${ }^{29}$ area of the color-Doppler mitral regurgitant jet in the left atrium (jet area), the narrowest diameter of the leak jet (vena contracta), the flow in the pulmonary veins and the effective regurgitant orifice (ERO) area. The degree of mitral regurgitation (MR) was classified into 3 grades [I (mild), II (moderate), III (severe)] according to the recommendations. ${ }^{29}$ The ERO area was determined by direct planimetry using RT-3DTEE and the QLAB multiplanar reconstruction tool (Philips Medical Systems), as previously described.$^{30}$ Also, the shape, width, length, and area of each PVL were analyzed and measured (Figure 3). The measurement of the area, width and length was also carried out by RT-3DTEE using the QLAB multiplanar reconstruction tool (Figure 4). RT-3DTEE findings were compared with surgical and fluoroscopy findings in patients who underwent redo surgical valve or percutaneous mitral PVL closure.

\section{Statistical Analysis}

Categorical variables are described as number (percentage) and were compared using the chi-square or Fisher's exact test, as appropriate. Continuous variables are described as mean \pm SD for variables with normal distribution or as median (range) for variables not normally distributed. Comparisons among normal continuous variables were made using Student's t-test; for variables not normally distributed, Mann-Whitney U tests were used. $\mathrm{P}<0.05$ was considered statistically significant. SPSS for Macintosh version 21.0 was used for statistical analysis. 


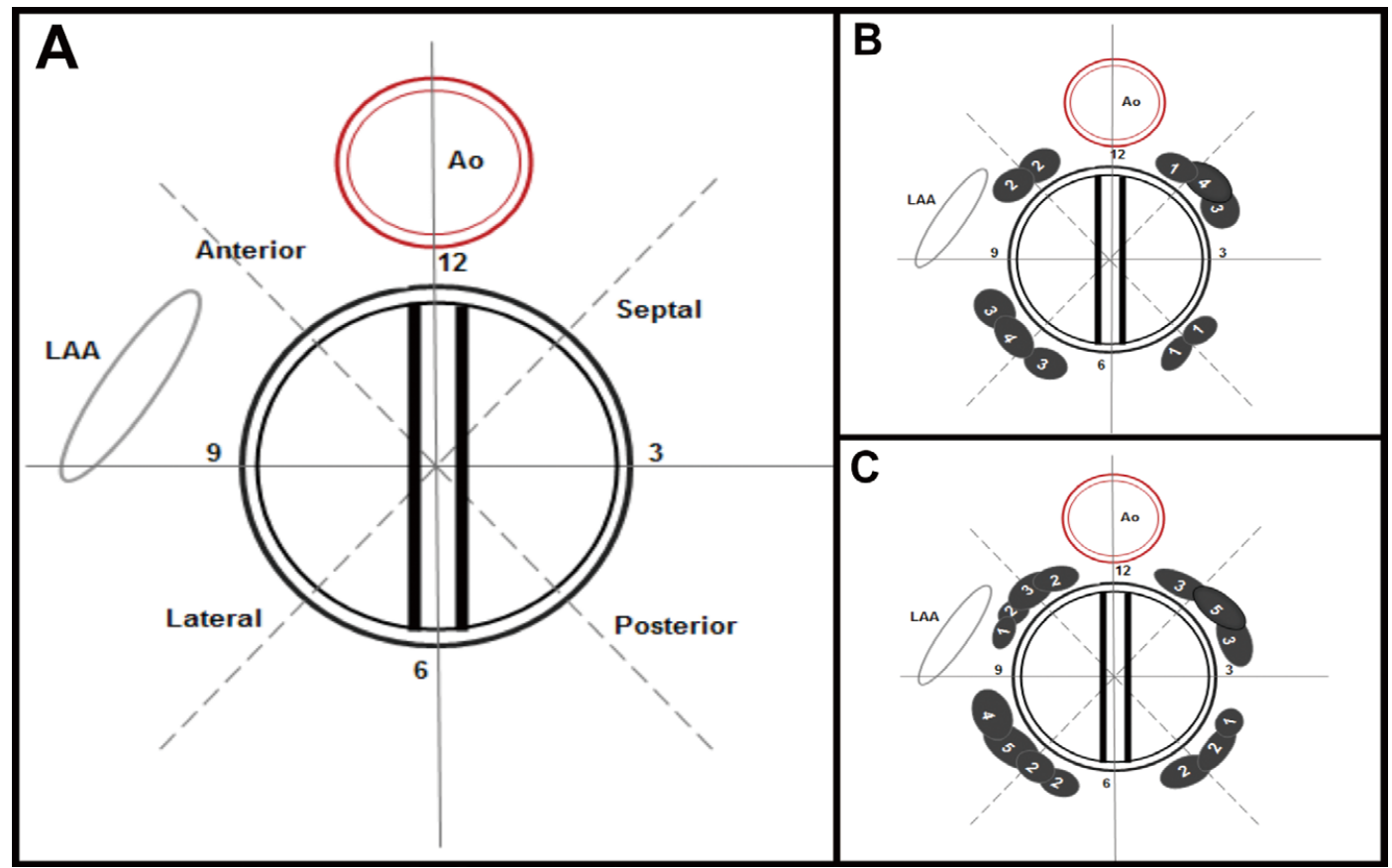

Figure 2. Schematics show the location of mitral paravalvular leaks (PVLs) in the "surgical view". (A) Anterior PVL (between 9 and 12 o'clock on the annulus), septal PVL (between 12 and 3 o'clock along the interatrial septum), posterior PVL (between 3 and 6 o'clock) and lateral PVL (between 6 and 9 o'clock). Mitral PVLs location according to (B) 2DTEE and (C) RT-3DTEE. Ao, aorta; LAA, left atrial appendage; RT, real time; TEE, transesophageal echocardiography.

\begin{tabular}{|lccc|}
\hline \multicolumn{2}{|l|}{ Table 1. Grading of Mitral Paravalvular Regurgitation by } & Echocardiography & \\
2D TEE & Mild & Moderate & Severe \\
Jet area $\left(\mathrm{cm}^{2}\right)$ & $<4$ & & \\
Vena contracta $(\mathrm{mm})$ & $<3$ & $4-9.9$ & $\geq 10$ \\
Pulmonary vein flow & Dominant systolic wave & Dominant diastolic wave & Systolic wave reversal \\
RT-3DTEE & & & \\
Vena contracta $(\mathrm{mm})$ & $<3$ & $3-6.9$ & $\geq 7$ \\
ERO area $\left(\mathrm{cm}^{2}\right)$ & $<0.2$ & $0.2-0.39$ & $\geq 0.4$ \\
\hline
\end{tabular}

ERO, effective regurgitant orifice; MPR, mitral paravalvular regurgitation; TEE, transesophageal echocardiography.

\section{Results}

Patient demographics and medical history are shown in Table 2. All patients had a mechanical prosthesis implanted $(91 \%$ bileaflet; $9 \%$ monoleaflet). There were 6 patients (18\%) with a history of redo valve surgery, and 5 patients (15\%) who had undergone percutaneous PVL closure. We achieved highquality $2 \mathrm{D}$ and $3 \mathrm{D}$ images of the prosthetic mitral valves, with a mean frame rate of $33 \pm 4$ and $13 \pm 3 \mathrm{~Hz}$, respectively.

Mitral PVLs were detected by 2DTEE and RT-3DTEE in 26 patients (76\%); 26 PVLs were identified by 2DTEE and 37 PVLs were identified by RT-3DTEE. Of the patients, $10(39 \%)$ had more than 1 PVL; 7 (27\%) patients had 2 PVLs and 3 (12\%) patients has $\geq 3$ PVLs (Table 3). Severe paravalvular MR by 2DTEE was present in $17(65 \%)$, moderate in $6(23 \%)$ and mild in $3(12 \%)$ patients. Severe paravalvular MR by RT3DTEE was present in $16(61 \%)$, moderate in $7(27 \%)$ and mild in $3(12 \%)$ patients $(\mathrm{P}>0.05)$ (Table 3$)$.

According to 2DTEE, the location of the 26 PVLs was septal in $10(38 \%)$, posterior in $2(8 \%)$, lateral in $8(31 \%)$ and anterior in 4 cases (15\%). The location of the PVL could not be specified in 2 cases $(8 \%)$. They were PVLs located in a posterior position and with very eccentric jets. According to RT-3DTEE, the location of the 37 PVLs was septal in 13 $(35 \%)$, posterior in $5(13 \%)$, lateral in $11(30 \%)$ and anterior in 8 cases $(22 \%)(\mathrm{P}>0.05)$ (Table 3$)$. They were identified by 2DTEE as 8 septal (73\%), 2 posterior (40\%), 10 lateral (77\%) and 4 anterior $(50 \%)$ PVLs. There was no right correspondence between 2DTEE and RT-3DTEE in 10 patients (38\%), in whom the location could not be established by 2DTEE or in whom more than 1 PVL was detected by RT-3DTEE (Table 3).

The median PVL size measured by RT-3DTEE was $7 \mathrm{~mm}$ long (range $3-36$ ) by $4 \mathrm{~mm}$ wide (range $2-10$ ). The median vena contracta of defect measured by $2 \mathrm{DTEE}$ and RT-3DTEE 


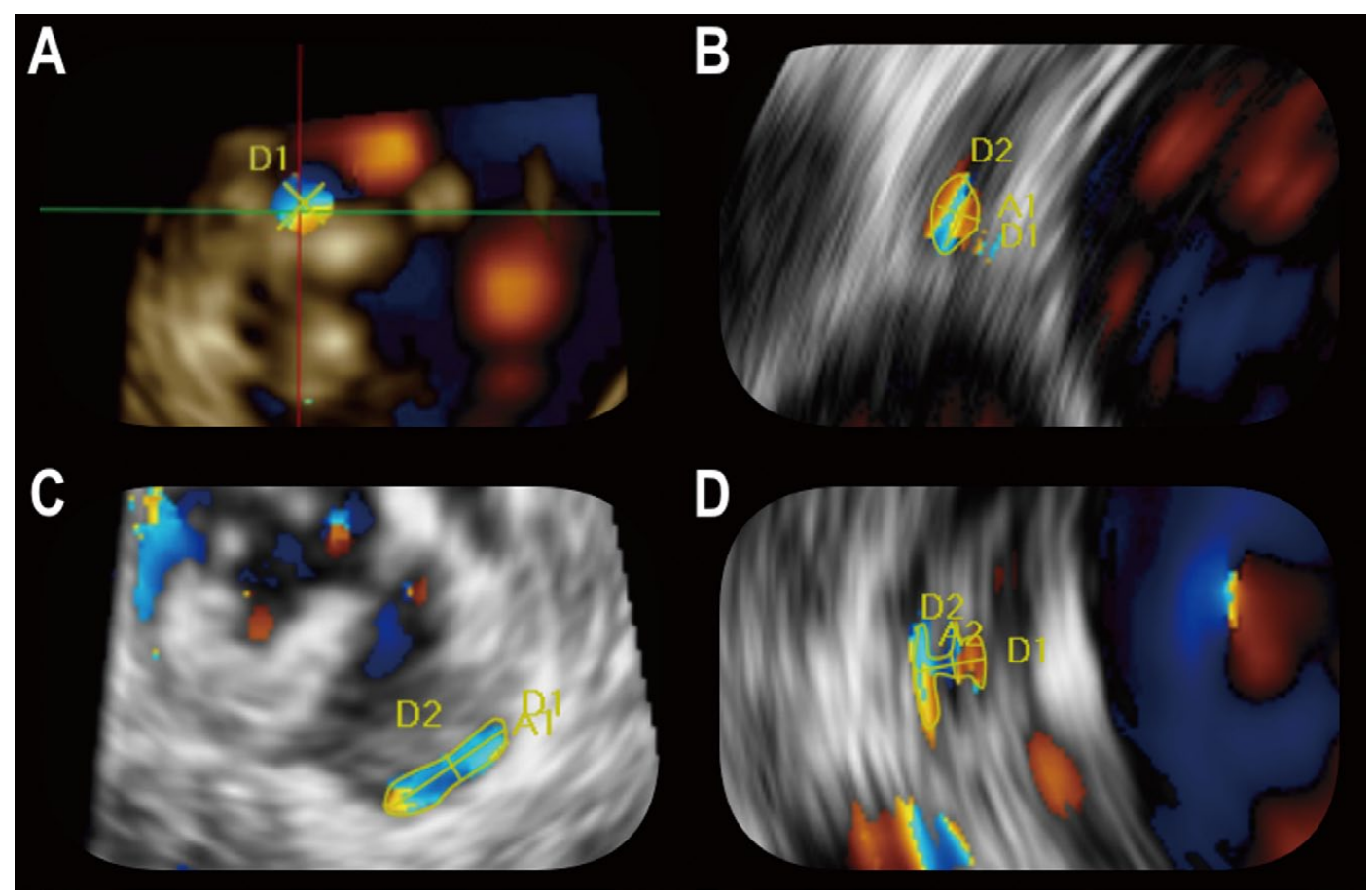

Figure 3. Shape of mitral paravalvular leaks. (A) Round: length of the defect equivalent to the width of the defect. (B) Oval: length of the defect greater than the width of the defect. (C) Crescent: defect has a half-moon or arc shape (D). Highly irregular: defect has cutting edges and could be multi-fenestrated.

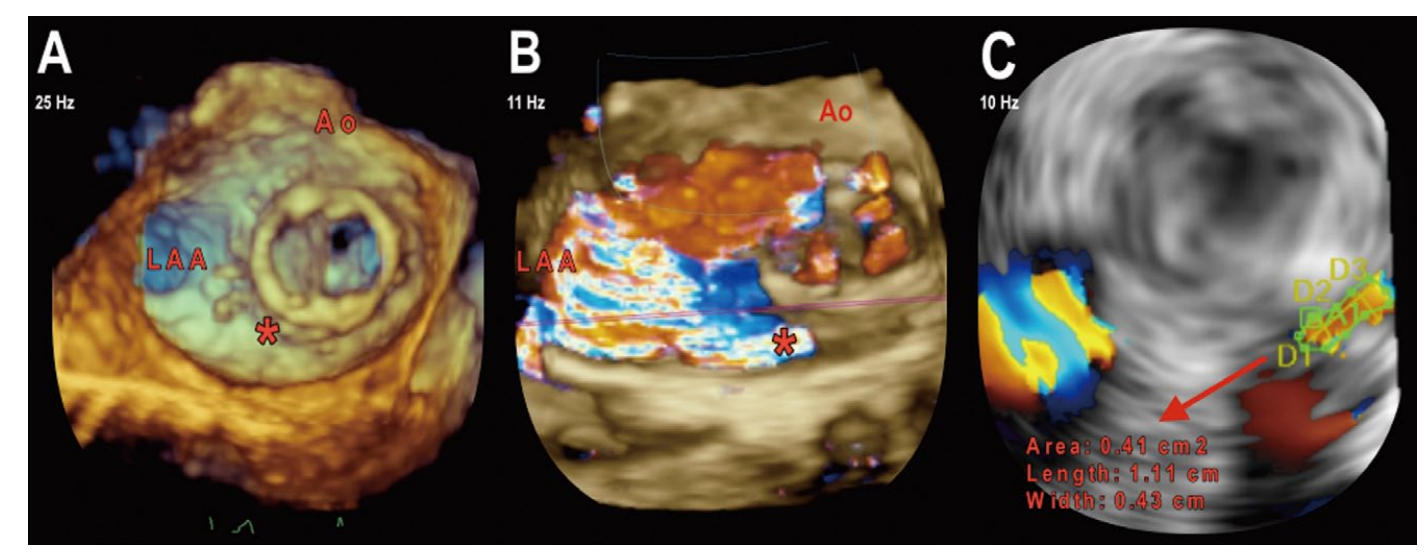

Figure 4. Evaluation of a mitral paravalvular leak (PVL) by real-time $3 \mathrm{D}$ transesophageal echocardiography (RT-3DTEE). (A) RT3DTEE imaging with asterisk identifying a lateral (7 o'clock) mitral PVL. (B) RT-3DTEE color-Doppler imaging with asterisk identifying the severe paravalvular mitral regurgitation. (C) Measurements of length, width, and area were performed by planimetry using the QLAB multiplanar reconstruction tool (Philips Medical Systems). Ao, aorta; LAA, left atrial appendage.

was $5 \mathrm{~mm}$ (range $3-8$ ) and $4 \mathrm{~mm}$ (range 2-10), respectively $(\mathrm{P}>0.05)$. The median ERO area of defect measured by RT3DTEE was $0.36 \mathrm{~cm}^{2}$ (range $0.15-2.10$ ); $0.18 \mathrm{~cm}^{2}$ (range $0.16-0.26$ ) for mild paravalvular MR, $0.29 \mathrm{~cm}^{2}$ (range $0.17-$ 0.51 ) for moderate paravalvular MR and $0.78 \mathrm{~cm}^{2}$ (range 0.24-2.10) for severe paravalvular MR (Table 3). The most common defect type by RT-3DTEE was "oval" ( $\mathrm{n}=20,54 \%)$. Also, there were 13 (35\%) "round", 3 (8\%) "crescent", and 1 (3\%) "highly irregular" shaped defects (Table 3). 2DTEE was not able to show these characteristics.

Surgical treatment was performed in 4 patients with heart failure and severe paravalvular MR. The site and dimensions 


\begin{tabular}{|c|c|}
\hline Mean age, years & $67 \pm 9$ \\
\hline Male sex, n (\%) & $17(51)$ \\
\hline \multicolumn{2}{|l|}{ Medical history } \\
\hline Hypertension, n (\%) & $9(26)$ \\
\hline Diabetes, n (\%) & $5(15)$ \\
\hline Coronary artery disease, $\mathrm{n}(\%)$ & $2(6)$ \\
\hline Atrial fibrillation, $\mathrm{n}(\%)$ & $22(65)$ \\
\hline Chronic renal failure, $\mathrm{n}(\%)$ & $4(12)$ \\
\hline Chronic obstructive pulmonary disease, $\mathrm{n}(\%)$ & $4(12)$ \\
\hline Prior stroke, n (\%) & $3(9)$ \\
\hline \multicolumn{2}{|l|}{ Prosthesis type } \\
\hline Mitral, n (\%) & $34(100)$ \\
\hline Mechanical prostheses, $\mathrm{n}(\%)$ & $34(100)$ \\
\hline - Bileaflet, $\mathrm{n}(\%)$ & $31(91)$ \\
\hline - Monoleaflet, n (\%) & $3(9)$ \\
\hline Time since valve surgery, months & $139[80-240]$ \\
\hline History of redo valve replacement, $\mathrm{n}(\%)$ & $6(18)$ \\
\hline History of percutaneous leak closure, $n(\%)$ & $5(15)$ \\
\hline \multicolumn{2}{|l|}{ Presenting symptoms } \\
\hline $\mathrm{HF}, \mathrm{n}(\%)$ & $20(59)$ \\
\hline Hemolytic anemia, n (\%) & $1(3)$ \\
\hline HF and hemolytic anemia, n (\%) & $13(38)$ \\
\hline NYHA class $\geq 111, n(\%)$ & $16(47)$ \\
\hline LV ejection fraction, \% & $57 \pm 5$ \\
\hline
\end{tabular}

HF, heart failure; LV, left ventricular; NYHA, New York Heart Association; PVL, paravalvular leak. of the dehiscence were all confirmed at the time of the surgery in each patient (100\%). Percutaneous closure of mitral PVLs was performed in 13 high-risk surgical patients with advanced heart failure and severe paravalvular MR. The site of the dehiscence was also all confirmed at the time of the procedure in each patient $(100 \%)$.

\section{Discussion}

This single-center study showed that RT-3DTEE is more effective than 2DTEE for establishing the number, location, size and shape of mitral PVLs.

Mitral PVLs are a well-recognized complication of mechanical or bioprosthetic surgical valve replacement, with a reported incidence of 7-17\%..$^{2-4}$ Most PVLs are small and clinically benign; however, larger PVLs can manifest as heart failure or hemolysis, necessitating either surgical or percutaneous repair. ${ }^{9}$

Echocardiography has an important role in the diagnosis of the PVL. RT-3DTEE can address the shortcomings of 2DTEE and demonstrate the exact number, sites, size, and shape of the PVLs. ${ }^{23,25}$ We had considerable difficulty in detecting more than 1 PVL with 2DTEE. However, with the help of RT-3DTEE it was relatively easy to detect all PVLs.

According to some authors, ${ }^{16,23,31,32}$ mitral PVLs occur more frequently at the anterolateral and posteromedial segments of the mitral valve annulus. In our study, the most common locations were septal and lateral. These discrepant finding could be in part related to the surgical technique and the implanted prosthesis, because the vast majority of surgeries were performed in the same center. On the other hand, we have also observed that there is not an absolute concordance between

\begin{tabular}{|c|c|c|c|}
\hline & 2DTEE & RT-3DTEE & $P$ value \\
\hline Number of patients with 1,2 and $\geq 3$ PVLs & & & 0.01 \\
\hline $1, \mathrm{n}(\%)$ & $26(100)$ & $16(61)$ & \\
\hline $2, \mathrm{n}(\%)$ & - & $7(27)$ & \\
\hline$\geq 3, \mathrm{n}(\%)$ & - & $3(12)$ & \\
\hline PVL location & & & NS \\
\hline Septal, n (\%) & $10(38)$ & $13(35)$ & \\
\hline Posterior, n (\%) & $2(8)$ & $5(13)$ & \\
\hline Lateral, n (\%) & $8(31)$ & $11(30)$ & \\
\hline Anterior, n (\%) & $4(15)$ & $8(22)$ & \\
\hline Not specified, n (\%) & $2(8)$ & - & \\
\hline Severity of paravalvular MR & & & NS \\
\hline Severe, n (\%) & $17(65)$ & $16(61)$ & \\
\hline Moderate, $\mathrm{n}(\%)$ & $6(23)$ & $7(27)$ & \\
\hline Mild, n (\%) & $3(12)$ & $3(12)$ & \\
\hline Median PVL size, mm (range) & - & $7(3-36)$ long $\times 4(2-10)$ wide & \\
\hline ERO area of the PVL, $\mathrm{cm}^{2}$ (range) & - & $0.36(0.15-2.10)$ & \\
\hline Mild regurgitation, $\mathrm{cm}^{2}$ (range) & - & $0.18(0.16-0.26)$ & \\
\hline Moderate regurgitation, $\mathrm{cm}^{2}$ (range) & - & $0.29(0.17-0.51)$ & \\
\hline Severe regurgitation, $\mathrm{cm}^{2}$ (range) & - & $0.78(0.24-2.10)$ & \\
\hline Vena contracta, mm (range) & $5(3-8)$ & $4(2-10)$ & NS \\
\hline \multicolumn{4}{|l|}{ PVL morphology } \\
\hline Oval, n (\%) & - & $20(54)$ & \\
\hline Round, n (\%) & - & $13(35)$ & \\
\hline Crescent, n (\%) & - & $3(8)$ & \\
\hline Highly irregular, n (\%) & - & $1(3)$ & \\
\hline
\end{tabular}

NS, P>0.05. MR, mitral regurgitation; 2DTEE, 2-dimensional TEE; RT-3DTEE, real-time 3-dimensional TEE. Other abbreviations as in Tables 1,2. 
locations given by 2DTEE and RT-3DTEE, because in 10 (38\%) there was not an exact match for the location. This happened in patients in whom the location of the PVL could not be established with 2DTEE and in patients with more than 1 PVL.

Although the morphology of the PVL is very complex, most reported leaks are either oval or crescent-shaped with irregular borders. ${ }^{33}$ In our study, oval-round and crescenticshaped PVLs comprised $97 \%$ of all PVLs. Note that the PVL shape is essential for the selection of the percutaneous treatment and the most adequate device in each case. The oval or crescent morphology of many PVLs makes it difficult to find a specific device that adapts to these defects. For this reason, a number of devices not specifically designed for this task have been used to treat PVLs, including atrial septal defect occluders, patent foramen ovale occluders, duct occluders, and muscular ventricular septal defect occluders. ${ }^{34-36}$ PVL size and location are other important factors in determining the most appropriate treatment and the most adequate device in each case. Also, RT-3DTEE now plays an important role during the closure procedure in the hemodynamics room, because it guides the operator during the different stages of the intervention, including the choice of site for atrial transseptal puncture, guiding the catheter and the device to the leak and immediate assessment of the results of the closure. ${ }^{37-39}$

We did not find significant differences in the degree of paravalvular MR evaluated by 2DTEE and RT-3DTEE. Only in 1 patient with a very eccentric regurgitant jet was the paravalvular MR assessed as severe by $2 \mathrm{DTEE}$ and as moderate by RT-3DTEE. Note that quantification of the severity of paravalvular MR in cases of multiple PVLs and/or eccentric jets is a real challenge. Color-Doppler in 3D echocardiography can be acquired together with a full volume, ${ }^{40,41}$ which is particularly useful in these complex cases. ${ }^{42}$ Also, other imaging techniques, such as computed tomography, could be useful for providing further information. ${ }^{12}$

Therefore, 2DTEE can be used for the diagnosis and quantification of paravalvular MR, but it is not sufficient for determining the characteristics and anatomical shape of the PVLs. RT-3DTEE provides excellent visualization of the mitral prosthesis ${ }^{43}$ and has become the technique of choice for the assessment of PVLs. However, RT-3DTEE presents some limits. It depends critically on the quality of the image, which requires a learning process in order to optimize its acquisition.

\section{Study Limitations}

First, this was a single-center study with a not very large population. Only patients with a prosthetic mitral valve were included. The assessment of prosthetic aortic valve by RT3DTEE is to some extent more limited than assessment of prosthetic mitral valve. Also, although we obtained high-resolution echocardiographic images, the mean frame rate was not very high. Finally, there is no gold standard for the localization of PVLs, such as fluoroscopy or surgical findings, to conclude that RT-3DTEE is superior to 2DTEE. However, in the patients who underwent surgery or percutaneous mitral PVL closure, the location and dimensions of the dehiscence were consistent with the RT-3DTEE findings.

\section{Conclusions}

RT-3DTEE permits detailed description of PVL characteristics compared with 2DTEE. This new technology may be very important in clinical decision-making and may contribute to the success of the potential corrective techniques.

\section{Disclosures}

None.

\section{References}

1. Beurtheret S, Gariboldi V, Feier H, Grisoli D, Riberi A, Mouly-Bandini A, et al. Short-term results of repeat valve replacement: A predictive factor analysis. J Heart Valve Dis 2010; 19: 326-332.

2. Echevarria JR, Bernal JM, Rabasa JM, Morales D, Revilla Y, Revuelta JM. Reoperation for bioprosthetic valve dysfunction: A decade of clinical experience. Eur J Cardiothorac Surg 1991; 5: $523-526$.

3. Ionescu A, Fraser AG, Butchart EG. Prevalence and clinical significance of incidental paraprosthetic valvar regurgitation: A prospective study using transoesophageal echocardiography. Heart 2003; 89: $1316-1321$.

4. Genoni M, Franzen D, Vogt P, Seifert B, Jenni R, Kunzli A, et al. Paravalvular leakage after mitral valve replacement: Improved longterm survival with aggressive surgery? Eur J Cardiothorac Surg 2000; 17: $14-19$.

5. Davila-Roman VG, Waggoner AD, Kennard ED, Holubkov R, Jamieson WR, Englberger L, et al. Prevalence and severity of paravalvular regurgitation in the Artificial Valve Endocarditis Reduction Trial (AVERT) echocardiography study. J Am Coll Cardiol 2004; 44: $1467-1472$.

6. Rallidis LS, Moyssakis IE, Ikonomidis I, Nihoyannopoulos P. Natural history of early aortic paraprosthetic regurgitation: A five-year followup. Am Heart J 1999; 138: 351-357.

7. Movsowitz HD, Shah SI, Ioli A, Kotler MN, Jacobs LE. Long-term follow-up of mitral paraprosthetic regurgitation by transesophageal echocardiography. J Am Soc Echocardiogr 1994; 7: 488-492.

8. O'Rourke DJ, Palac RT, Malenka DJ, Marrin CA, Arbuckle BE, Plehn JF. Outcome of mild periprosthetic regurgitation detected by intraoperative transesophageal echocardiography. J Am Coll Cardiol 2001; 38: $163-166$.

9. Latson LA. Transcatheter closure of paraprosthetic valve leaks after surgical mitral and aortic valve replacements. Expert Rev Cardiovasc Ther 2009; 7: 507-514.

10. Miller DL, Morris JJ, Schaff HV, Mullany CJ, Nishimura RA, Orszulak TA. Reoperation for aortic valve periprosthetic leakage: Identification of patients at risk and results of operation. J Heart Valve Dis 1995; 4: $160-165$.

11. Sorajja P, Cabalka AK, Hagler DJ, Rihal CS. Percutaneous repair of paravalvular prosthetic regurgitation: Acute and 30-day outcomes in 115 patients. Circ Cardiovasc Interv 2011; 4: 314-321.

12. Ruiz CE, Jelnin V, Kronzon I, Dudiy Y, Del Valle-Fernandez R, Einhorn BN, et al. Clinical outcomes in patients undergoing percutaneous closure of periprosthetic paravalvular leaks. J Am Coll Cardiol 2011; 58: 2210-2217.

13. Krishnaswamy A, Kapadia SR, Tuzcu EM. Percutaneous paravalvular leak closure- imaging, techniques and outcomes. Circ J 2013; 77: $19-27$.

14. Matsumoto M, Inoue M, Tamura S, Tanaka K, Abe H. Three-dimensional echocardiography for spatial visualization and volume calculation of cardiac structures. J Clin Ultrasound 1981; 9: 157-165.

15. Singh P, Manda J, Hsiung MC, Mehta A, Kesanolla SK, Nanda NC, et al. Live/real time three-dimensional transesophageal echocardiographic evaluation of mitral and aortic valve prosthetic paravalvular regurgitation. Echocardiography 2009; 26: 980-987.

16. Gursoy OM, Astarcioglu MA, Gokdeniz T, Aykan AC, Bayram Z, Cakal B, et al. Severe mitral paravalvular leakage: Echo-morphologic description of 47 patients from real-time three-dimensional transesophageal echocardiography perspective. Anadolu Kardiyol Derg 2013; 13: $633-640$.

17. Shiota T. Clinical application of 3-dimensional echocardiography in the USA. Circ J 2015; 79: 2287-2298.

18. Lee AP, Fang F, Jin CN, Kam KK, Tsui GK, Wong KK, et al. Quantification of mitral valve morphology with three-dimensional echocardiography: Can measurement lead to better management? Circ J 2014; 78: 1029-1037.

19. Vecera J, Bartunek J, Vanderheyden M, Kotrc M, Kockova R, Penicka M. Three-dimensional echocardiography-derived vena contracta area at rest and its increase during exercise predicts clinical outcome in mild-moderate functional mitral regurgitation. Circ J 2014; 78: $2741-2749$

20. Park JS, Hong YS, Choi BJ, Choi SY, Yoon MH, Hwang GS, et al. Abscess pocket in the vegetation confirmed on 3-dimensional transesophageal echocardiography. Circ J 2014; 78: 1995-1996.

21. Eng MH, Salcedo EE, Quaife RA, Carroll JD. Implementation of real 
time three-dimensional transesophageal echocardiography in percutaneous mitral balloon valvuloplasty and structural heart disease interventions. Echocardiography 2009; 26: 958-966.

22. Manda J, Kesanolla SK, Hsuing MC, Nanda NC, Abo-Salem E, Dutta R, et al. Comparison of real time two-dimensional with live/ real time three-dimensional transesophageal echocardiography in the evaluation of mitral valve prolapse and chordae rupture. Echocardiography 2008; 25: 1131-1137.

23. Kronzon I, Sugeng L, Perk G, Hirsh D, Weinert L, Garcia Fernandez $\mathrm{MA}$, et al. Real-time 3-dimensional transesophageal echocardiography in the evaluation of post-operative mitral annuloplasty ring and prosthetic valve dehiscence. J Am Coll Cardiol 2009; 53: 1543 1547.

24. Badano LP, Boccalini F, Muraru D, Bianco LD, Peluso D, Bellu R, et al. Current clinical applications of transthoracic three-dimensional echocardiography. J Cardiovasc Ultrasound 2012; 20: 1-22.

25. Garcia-Fernandez MA, Cortes M, Garcia-Robles JA, Gomez de Diego JJ, Perez-David E, Garcia E. Utility of real-time three-dimensional transesophageal echocardiography in evaluating the success of percutaneous transcatheter closure of mitral paravalvular leaks. $J$ Am Soc Echocardiogr 2010; 23: 26-32.

26. Groundstroem K, Rittoo D, Hoffman P, Bloomfield P, Sutherland GR. Additional value of biplane transoesophageal imaging in assessment of mitral valve prostheses. Br Heart J 1993; 70: 259-265.

27. Meloni L, Aru GM, Abbruzzese PA, Cardu G, Martelli V, Cherchi A. Localization of mitral periprosthetic leaks by transesophageal echocardiography. Am J Cardiol 1992; 69: 276-279.

28. Cortes M, Garcia E, Garcia-Fernandez MA, Gomez JJ, Perez-David E, Fernandez-Aviles F. Usefulness of transesophageal echocardiography in percutaneous transcatheter repairs of paravalvular mitral regurgitation. Am J Cardiol 2008; 101: 382-386.

29. Zoghbi WA, Chambers JB, Dumesnil JG, Foster E, Gottdiener JS, Grayburn PA, et al. Recommendations for evaluation of prosthetic valves with echocardiography and doppler ultrasound: A report From the American Society of Echocardiography's Guidelines and Standards Committee and the Task Force on Prosthetic Valves, developed in conjunction with the American College of Cardiology Cardiovascular Imaging Committee, Cardiac Imaging Committee of the American Heart Association, the European Association of Echocardiography, a registered branch of the European Society of Cardiology, the Japanese Society of Echocardiography and the Canadian Society of Echocardiography, endorsed by the American College of Cardiology Foundation, American Heart Association, European Association of Echocardiography, a registered branch of the European Society of Cardiology, the Japanese Society of Echocardiography, and Canadian Society of Echocardiography. J Am Soc Echocardiogr 2009; 22: 975-1014.

30. Franco E, Almeria C, de Agustin JA, Arreo Del Val V, Gomez de Diego JJ, Garcia Fernandez MA, et al. Three-dimensional color Doppler transesophageal echocardiography for mitral paravalvular leak quantification and evaluation of percutaneous closure success. J Am
Soc Echocardiogr 2014; 27: 1153-1163.

31. Yildiz M, Duran NE, Gokdeniz T, Kaya H, Ozkan M. The value of real-time three-dimensional transesophageal echocardiography in the assessment of paravalvular leak origin following prosthetic mitral valve replacement. Turk Kardiyol Dern Ars 2009; 37: 371-377.

32. De Cicco G, Russo C, Moreo A, Beghi C, Fucci C, Gerometta P, et al. Mitral valve periprosthetic leakage: Anatomical observations in 135 patients from a multicentre study. Eur J Cardiothorac Surg 2006; 30: $887-891$.

33. Perk G, Lang RM, Garcia-Fernandez MA, Lodato J, Sugeng L, Lopez J, et al. Use of real time three-dimensional transesophageal echocardiography in intracardiac catheter based interventions. $J \mathrm{Am}$ Soc Echocardiogr 2009; 22: 865-882.

34. Binder RK, Webb JG. Percutaneous mitral and aortic paravalvular leak repair: Indications, current application, and future directions. Curr Cardiol Rep 2013; 15: 342.

35. Pate GE, Thompson CR, Munt BI, Webb JG. Techniques for percutaneous closure of prosthetic paravalvular leaks. Catheter Cardiovasc Interv 2006; 67: 158-166.

36. Kort HW, Sharkey AM, Balzer DT. Novel use of the Amplatzer duct occluder to close perivalvar leak involving a prosthetic mitral valve. Catheter Cardiovasc Interv 2004; 61: 548-551.

37. Anwar AM, Nosir YF, Zainal-Abidin SK, Ajam A, Chamsi-Pasha H. Real-time three-dimensional transthoracic echocardiography in daily practice: Initial experience. Cardiovasc Ultrasound 2012; 10: 14

38. Mele D, Agricola E, Dal Monte A, Ancona MB, Ferrari R. Perivalvular leak assessment and closure: Role of real-time three-dimensional transesophageal echocardiography. G Ital Cardiol 2012; 13: 38-46.

39. Cruz-González I, Rama-Merchan JC, Arribas-Jimenez A, RodriguezCollado J, Martin-Moreiras J, Cascon-Bueno M, et al. Paravalvular leak closure with the Amplatzer Vascular Plug III device: Immediate and short-term results. Rev Esp Cardiol 2014; 67: 608-614.

40. Sordi M, Brochet E, Messika-Zeitoun D. Mitral paravalvular leak detected by three-dimensional transoesophageal echocardiography. Arch Cardiovasc Dis 2013; 106: 627-628.

41. Tarantini G, Mojoli M, Napodano M. Mitral paravalvular leak closure by antegrade percutaneous approach: Three-dimensional transesophageal echocardiographic guided multiple Amplatzer implantation by a modified sequential anchoring-based technique. Catheter Cardiovasc Interv 2013; 82: 626-629.

42. Biner S, Kar S, Siegel RJ, Rafique A, Shiota T. Value of color Doppler three-dimensional transesophageal echocardiography in the percutaneous closure of mitral prosthesis paravalvular leak. Am J Cardiol 2010; 105: 984-989.

43. Sugeng L, Shernan SK, Weinert L, Shook D, Raman J, Jeevanandam $\mathrm{V}$, et al. Real-time three-dimensional transesophageal echocardiography in valve disease: Comparison with surgical findings and evaluation of prosthetic valves. J Am Soc Echocardiogr 2008; 21: $1347-1354$ 